\title{
ÉTICA NO SERVIÇO PÚBLICO FEDERAL: CONTEXTO E REFLEXÕES
}

\author{
K. C. CATAFESTA \\ Instituto Federal de Rondônia - IFRO \\ kelly.catafesta@ifro.edu.br
}

Submetido 08/10/2016 - Aceito 20/12/2016

DOI: $10.15628 /$ holos.2017.5175

\section{RESUMO}

O objetivo do presente ensaio é contextualizar a ética no serviço público federal por meio do código de ética dos servidores públicos federais. Para o alcance do objetivo proposto utilizou-se como metodologia a pesquisa bibliográfica de autores que propõem um debate sobre os conceitos de ética e moral, a importância da elaboração de códigos de ética para as categorias profissionais e os conceitos e deveres do código de ética dos servidores públicos federais. Os resultados alcançados após a conclusão da pesquisa demonstram que a conduta ética de um grupo é regida pela aceitação coletiva dos conceitos morais. Os códigos de ética são elaborados para compilar as normas e condutas que orientam os profissionais de determinada categoria profissional. Desta forma, o Decreto no 1.171/94 institui os parâmetros de ética que devem ser observados pelos servidores públicos federais.

PALAVRAS-CHAVE: Ética; Moral; Código de Ética; Servidor público federal; Decreto no 1.171/94.

\section{ETHICS IN THE FEDERAL PUBLIC SERVICE: CONTEXT AND REFLECTIONS}

\begin{abstract}
The objective of this study is to contextualize ethics in results can be inferred after the conclusion of the the federal public service through the ethical code of research is que the ethical conduct of a group is federal civil servants. To achieve the proposed objective governed by collective acceptance of moral concepts. was used the research methodology the literature of Codes of ethics are designed to compile the standards authors who proposes to on debate the concepts of and behaviors of guide professionals in a certain ethics and morals, the importance of developing codes of profession. Therefore, the Decree no. 1.171/94 institute ethics for the professional categories and concepts and the parameters of ethics to be observed by federal public duties of the code ethics of federal civil servants. The servants.
\end{abstract}

KEYWORDS: Ethics; Morals; Code of ethics; Federal public servants; Decree 1.171/94. 


\section{INTRODUÇÃO}

A ética permeia a vida dos indivíduos desde sua concepção e provoca discussões conceituais desde os tempos antigos, tendo em filósofos consagrados como Sócrates (399 a.C.) e Aristóteles (385 a.C.) seu berço filosófico.O conceito de ética é provocativo, pois deriva do consciente, está intrinsicamente relacionado com o entendimento de moral e os traços de caráter de cada pessoa e se conceitua externamente através da expressão individual culminando com a consolidação coletiva (BARROCO, 2001).

Os homens enfrentam determinados problemas nas suas relações mútuas, tomam decisões e realizam certos atos para resolvê-los e ao mesmo tempo avaliam estas decisões e estes atos, refletindo sobre o comportamento prático (VÁSQUEZ, 1995). As discussões éticas e das práticas da moral definem a conduta ética e os valores da moral aceitos pelo grupo social. Segundo Cortella (2007), a ética é o conjunto de princípios e valores da nossa conduta na vida junta. É o que faz a fronteira entre o que a natureza manda e o que nós decidimos. A ética é aquilo que orienta a sua capacidade de decidir, julgar, avaliar. Só é possível falar em ética quando falamos em seres humanos, porque ética pressupõe a capacidade de decidir, julgar e avaliar com autonomia.

Nesse meandro, as classes profissionais elaboram o código de ética que rege a sua atuação profissional. De acordo com Alves (2007) os códigos de ética contêm os padrões morais que os profissionais de uma determinada classe devem aceitar e observar e têm como objetivo regular as relações entre os membros dessa categoria, bem como entre ela e a sociedade, de maneira impositiva.

No serviço público federal, o Decreto no 1.171/94 visa instituir as regras, princípios, deveres e proibições que devem ser observados no exercício da carreira. A conduta ética do servidor público não é apenas uma questão de comportar-se de acordo com o que é permitido. 0 essencial é a orientação interna que ele dá a suas ações: a motivação, o esmero, o gosto com que realiza seu ofício para cumprir seus deveres ou para fazer mais do que a função lhe prescreve (ENAP, 2012).

Porém perduram encravadas no senso comum brasileiro a visão distorcida e até caricata da ausência de moral e ética no serviço público. A opinião pública é concordante de que o grau de obediência a princípios éticos é muito baixo no serviço público e revela um ceticismo intrínseco do povo em relação ao padrão ético do aparelho de Estado (CARNEIRO, 1998). Todavia, os servidores públicos federais estão condicionados a observar os preceitos do código de ética instituído no Decreto no 1.171/94 bem como estão sujeitos ao Código Penal, ao Código Civil e a Lei de Responsabilidade Fiscal.

Portanto, instrumentos não faltam para que se assegure ao funcionalismo público um bom funcionamento pautado no agir ético. O presente ensaio teórico delimita-se a pesquisar os princípios de condutas éticas, contextualizar o código de ética por meio do Decreto no 1.171/94 e instigar a reflexão de hipóteses que refletem na falta de credibilidade junto à sociedade.

Para o alcance do objetivo do presente estudo utilizou-se como metodologia a pesquisa bibliográfica, onde autores variados propõem um debate sobre os conceitos de ética e moral, a importância da elaboração de códigos de ética para as categorias profissionais e os conceitos e deveres do código de ética dos servidores públicos federais. Concluiu-se que o código de ética dos servidores abrange as dimensões relativas ao comportamento, conceitos e deveres que os profissionais devem observar e que para uma melhoria na efetividade do alcance das diretrizes 
instituídas devem ser desenvolvidas ações educativas com finalidade de instituir na cultura dos departamentos a sua observância.

Necessário faz-se investir no trabalho pedagógico de disseminação dos preceitos do código de ética do serviço público federal, com vistas a ampliar sua compreensão, instituí-lo na cultura organizacional e culminar com o julgamento ético na ação que o servidor realiza, e são estas ações a serem trilhadas incessantemente na administração pública (CARNEIRO, 1998).

\section{Conceito de ética e conduta ética}

O surgimento do termo ética remonta a tempos antigos, tendo como seus precursores filósofos consagrados como Sócrates (399 a.C.)e Aristóteles (385 a.C.), sendo Sócrates considerado o pai da ética, seu instituidor. De acordo com Hegel (1989), Sócrates celebrizou-se como mestre de moral e foi ele que proclamou a supremacia do pensamento como o determinante das ações. Os gregos tinham eticidade, mas Sócrates se propôs a lhes ensinar as virtudes, os deveres, e morais que o homem deve ter. $O$ homem moral não é o que quer e faz a justiça, não é o homem inocente, mas sim o que tem consciência de sua ação. As histórias antigas da filosofia destacam, como um dos méritos de Sócrates, o fato dele ter introduzido a ética como um novo conceito da história da filosofia, que, até então, somente se ocupava de investigar a natureza (HEGEL, 1989).

O caráter do indivíduo preceitua a origem da moral que, conforme Singer (2002, p.42), pode ser entendida como "o conjunto das práticas cristalizadas pelos costumes e convenções histórico-sociais". A moral caracteriza um sistema de normas, princípios e valores, segundo os quais são regulamentadas as relações mútuas entre os indivíduos ou entre estes e a comunidade, de tal maneira que estas normas, dotadas de um caráter histórico e social, sejam acatadas livres e conscientemente, por uma convicção íntima, e não de uma maneira mecânica, externa ou impessoal (VÁSQUEZ, 1995).

De acordo com Barroco (2001), a moral é construída pelo caráter de um indivíduo que somado aos dos demais indivíduos de uma sociedade resulta nos princípios e valores comumente aceitos e tidos como corretos, norteadores do comportamento social. Ainda segundo o autor, a moral expressa a identidade cultural de uma sociedade, de uma classe, de um estrato social, num determinado momento histórico. E pelo fato de o indivíduo aceitar intimamente os valores, passa a fazer parte do seu caráter e a compor o grupo com o qual desenvolve os vínculos sociais. Essas percepções de moralidade dos indíviduos fazem parte da história da humanidade, assim como no passado o regime de escravidão de pessoas negras era prática comum e aceita coletivamente pelos indivíduos nos tempos atuais é abominada pela sociedade e moralmente condenada.

Dessa forma, caráter se refere às características pessoais de cada um que determinam quais virtudes e quais vícios cada um é capaz de praticar. Referem-se, portanto, ao senso moral e à consciência ética individuais (CHAUÍ, 1999). Da subjetividade, a moral emerge em conflitos sociais, pois sendo sua origem no íntimo de cada indivíduo e tendo sua formação na aceitação coletiva por um conjunto de indivíduos vivendo em sociedade em determinado período histórico, não há uma moral absoluta a todos os homens, pois a moral absoluta depende da aceitação de todos os indivíduos, onde não ocorra a divergência de pensamentos e aceitações dos conceitos morais (BARROCO, 2001).

Os homens não só agem moralmente (isto é, enfrentam determinados problemasnas suas relações mútuas, tomam decisões e realizam certos atos para resolvê-los e, ao mesmo tempo, julgam ou avaliam de uma ou de outra maneira estas decisões e estes atos), mas também refletem sobre esse comportamento prático e o tomam como objeto 
da sua reflexão e do seu pensamento. Dá-se assim a passagem do plano da prática moral para o da teoria moral; ou, em outras palavras, da moral efetiva, vivida, para a moral reflexa. Quando se verifica esta passagem, que coincide com os inícios do pensamento filosófico, já estamos propriamente na esfera dos problemas teórico-morais ou éticos. (VÁSQUEZ, 199, p. 17)

A conduta moral deve estar relacionada não somente com a subjetividade do pensamento e comportamento humano, segundo Chauí (1999) é necessário também considerar a capacidade de racionalização e análise dos impactos da ação praticada, aliando dessa forma o subjetivo ao racional.Temos então que a conduta ética moral é praticada pelo indivíduo capaz de autodeterminar-se e agir conscientemente. Ainda segundo Chauí (1999), é sujeito ético moral somente aquele que sabe o que faz, conhece as causas e os fins de sua ação, o significado de suas intenções e de suas atitudes e a essência dos valores morais.

A reflexão ética supõe a suspensão da cotidianidade e não tem por objetivo responder às suas necessidades imediatas, mas sistematizar a crítica da vida cotidiana (BARROCO, 2001).

Ser consciente de si e dos outros, isto é, ser capaz de reflexão e de reconhecer a existência dos outros como sujeitos éticos iguais a ele; Ser dotado de vontade, isto é, de capacidade para controlar e orientar desejos, impulsos, tendências, sentimentos (para que estejam em conformidade com a consciência) e de capacidade para deliberar e decidir entre várias alternativas possíveis; Ser responsável, isto é, reconhecer-se como autor da ação, avaliar os efeitos e consequências dela sobre si e sobre os outros, assumila bem como às suas consequências, respondendo por elas; Ser livre, isto é, ser capaz de oferecer-se como causa interna de seus sentimentos atitudes e ações, por não estar submetido a poderes externos que o forcem e o constranjam a sentir, a querer e fazer alguma coisa. A liberdade não é tanto o poder para escolher entre vários possíveis, mas o poder para o autodeterminar-se, dando a si mesmo as regras de conduta (CHAUÍ, 1999, p.337-338).

Dessa forma, chegamos aos limiares do conceito de ética, de acordo com Vásquez (1995) "a ética é teoria, investigação ou explicação de um tipo de experiência humana ouforma de comportamento dos homens, o da moral, considerado, porém, na suatotalidade, diversidade e variedade". Ainda segundo o autor, "o ético transforma-se assim numa espécie de legislador do comportamento moral dos indivíduos ou da comunidade. Mas a função fundamental da ética é a mesma de toda teoria: explicar, esclarecer ou investigarnuma determinada realidade, elaborando os conceitos correspondentes".

Segundo Cortella (2007), a ética é aquilo que orienta a sua capacidade de decidir, julgar, avaliar. Por isso, só é possível falar em ética quando falamos em seres humanos, porque ética pressupõe a capacidade de decidir, julgar, avaliar com autonomia.

A ética é parte do cotidiano dos seres humanos e das sociedades, sendo estabelecida, praticada e desenvolvida nas relações humanas conforme o desenvolver e amadurecer do coletivo. Ser consciente da ética e moral pressupõe a conduta ética por parte dos indivíduos, que pode ser estabelecida em códigos e regras, expressas em documentos ou não, podendo, também, ser meio do consciente coletivo, pressuposto de existência e observação por todos os seus integrantes. Aética depara com uma experiência histórico social no terreno da moral, ou seja, a partir das práticas de moral existentes, busca determinar a essência da moral, e as condições objetivas e subjetivas do ato moral, as fontes da avaliação moral, a natureza e a função dos juízos morais, os critérios de justificação destes juízos e o princípio que rege a mudança e a sucessão de diferentes sistemas morais (VÁSQUEZ, 1995). 


\section{Código de ética como guia de conduta do comportamento}

De acordo com Motta (1984), a ética profissional é o conjunto de normas de conduta que deverão ser postas em prática no exercício de qualquer profissão. E tem como objetivo o relacionamento do profissional com sua clientela e vice-versa, tendo em vista, principalmente, a dignidade do homem e o bem-estar do contexto sociocultural em que atua sua profissão. Para compilar estes conjuntos de normas e condutas são elaborados os códigos de ética que buscam orientar os profissionais de determinada área para uma atuação dentro dos preceitos da categoria profissional. Nahistória da humanidade há registros das primeiras civilizações utilizarem a escrita e constituírem regimentos balizadores de conduta e convivência em sociedade (NEVES, 2009). O mais notório é o Código de Hamurabi que fixava as leis, os costumes e tradições para o povo do império Sumério.

Sob o ponto de vista ético e social e pela segurança de sua datação, o Código de Hamurabi pode ser considerado um documento universal, que apresenta codificação clara e breve do direito privado numa época histórica remotíssima. Voltado à orientação do povo do Império Sumerino fixava os costumes e as tradições jurídicas já seculares no país. (...)Embora, para os padrões atuais, esse Código, sem dúvida, possa ser considerado demasiado severo, tendo se originado, provavelmente, na mal-practice, denota que desde aquela época já se percebia a importância de regulamentar não apenas o comportamento social, mas também as práticas profissionais, especialmente nos casos em que afetam diretamente a vida dos indivíduos e da comunidade, como é o caso da medicina. (NEVES, 2009, p.111)

Segundo VÁSQUEZ (1995), a ética é a teoria ou ciência do comportamento moral dos homens em sociedade, é ciência de uma forma específica de comportamento humanoe para tanto, expressar as regras e conduta do comportamento profissional, a elaboração de um código de ética é de sumaríssima importância. De acordo com MOREIRA (2002, p.33), "O Código de Ética, quando adotado, implantado de forma correta e regularmente obedecido, pode constituir uma prova legal da determinação da administração da empresa, de seguir os preceitos nele refletidos".

No código de ética devem conter os padrões morais que uma determinada classe profissional deve observar e servirá também para regular as relações entre os membros dessa categoria e para com a sociedade. $\mathrm{O}$ código de ética tem o objetivo de proteger a sociedade e a classe profissional da atuação de maus profissionais. Dessa forma, ele torna-se um documento orientativo e seu descumprimento pode acarretar punições ao indivíduo. A elaboração de um código de ética observará princípios considerados fundamentais para a conduta profissional dos indivíduos. No conceito de Schwartz(2002, apud SILVA, 2009), os códigos de ética devem ser regidos por seis princípios básicos: confiabilidade (honestidade, integridade, lealdade), respeito (direitos humanos), responsabilidade (assumir as responsabilidades pelos atos decorrentes de suas atividades), ser justo (imparcialidade), ser cuidadoso (evitar danos ou prejuízos desnecessários) e cidadania (obedecer à lei).

Porém, é cabível salientar que o código de ética talvez não abranja com total dimensão todas as situações que um profissional enfrenta no seu dia a dia, principalmente nas profissões com maior contato com outros seres humanos, vide as áreas de saúde e psicologia, em que os profissionais estarão expostos às situações totalmente imprevisíveis e que não estarão descritas em nenhuma manual ou código pré-elaborado.Ao mesmo tempo em que um código de normas explícitas se torna necessário, ressalta-se que a moralidade se concebe como atitude, qualidade e 
valores e que a ética não pode proporcionar soluções pré-fabricadas, sem que haja um trabalho interno de cada indivíduo que se propõe a agir eticamente (Conselho Federal de Psicologia, 1996, apud TOMANIK, 2008).

\section{4. Ética no serviço público federal}

No serviço público federal o Decreto no 1.171, de 22 de junho de 1994, aprovado pelo então presidente da República, Itamar Franco, institui o código de ética profissional do servidor civil do poder executivo federal. Seu texto contém as regras deontológicas ${ }^{1}$, deveres, proibições e institui as comissões de ética. Tem como finalidade orientar as relações internas entre os servidores e outros colaboradores, as relações com outras entidades públicas ou privadas e as relações com o cidadão (ENAP, 2012). Em sua elaboração foram consideradas as disposições do Art. 37 da Constituição Federal Brasileira, que trata dos preceitos da Administração Pública e os deveres e proibições aos servidores públicos federais estipulados na Lei 8.112/90.

No código de ética do servidor público federal estão estipulados como principais deveres do servidor: desempenhar, a tempo, as atribuições do cargo, função ou emprego público de que seja titular;exercer suas atribuições com rapidez, perfeição e rendimento, pondo fim ou procurando prioritariamente resolver situações procrastinatórias, principalmente diante de filas ou de qualquer outra espécie de atraso na prestação dos serviços pelo setor em que exerça suas atribuições, com o fim de evitar dano moral ao usuário;ser probo, reto, leal e justo, demonstrando toda a integridade do seu caráter, escolhendo sempre, quando estiver diante de duas opções, a melhor e a mais vantajosa para o bem comum (BRASIL, 1994).

Também é estipulado jamais retardar qualquer prestação de contas, condição essencial da gestão dos bens, direitos e serviços da coletividade a seu cargo; tratar cuidadosamente os usuários dos serviços aperfeiçoando o processo de comunicação e contato com o público; ter consciência de que seu trabalho é regido por princípios éticos que se materializam na adequada prestação dos serviços públicos; ser cortês, ter urbanidade, disponibilidade e atenção, respeitando a capacidade e as limitações individuais de todos os usuários do serviço público, sem qualquer espécie de preconceito ou distinção de raça, sexo, nacionalidade, cor, idade, religião, cunho político e posição social, abstendo-se, dessa forma, de causar-lhes dano moral;ter respeito à hierarquia, porém sem nenhum temor de representar contra qualquer comprometimento indevido da estrutura em que se funda o Poder Estatal (BRASIL, 1994).

$O$ código de ética também orienta que os servidores não permitam que interesses de ordem pessoal interfiram no trato com o público ou com os colegas de trabalho, praticar qualquer ato com vistas a prejudicar ou beneficiar terceiros ou a si próprio, dentre outros, guia os servidores públicos federais sobre as condutas e comportamento a serem seguidos no exercício da profissão, criando, portanto, a ética necessária para execução das atividades enquanto servidor federal.

Além do Decreto no 1.171/94, existe também o Código de Conduta da Alta Administração Federal que foi aprovado pelo Presidente da República, Fernando Henrique Cardoso, em 21 de agosto de 2000. É destinado aos segmentos mais elevados da hierarquia governamental, como Ministros e Secretários de Estados, com as diretrizes de tornar claras as regras de conduta das autoridades da Alta Administração Federal e proporcionar à sociedade percepção de integridade e lisura das decisões governamentais (AMORIM, 2000).

\footnotetext{
${ }^{1}$ Deontológica - tratado dos deveres e da moral.
} 
O objetivo do Código de Conduta da Alta Administração Federal é estipular regras de conduta das autoridades citadas com vistas a garantir a integridade e lisura do processo decisório governamental, aperfeiçoar os padrões éticos da Administração Pública Federal e minimizar a possibilidade de conflito entre o interesse privado e o dever funcional das autoridades públicas (BRASIL, 2000).

A elaboração deste Código contou com o auxílio da Comissão de Ética Pública - CEP, criada pelo Decreto de 26 de maio de 1999, competindo-lhe atuar como instância consultiva do Presidente da República e Ministros de Estado em matéria de ética pública; administrar a aplicação do Código de Conduta da Alta Administração Federal, devendo submeter ao Presidente da República medidas para seu aprimoramento; dirimir dúvidas a respeito de interpretação de suas normas, deliberando sobre casos omissos; apurar, mediante denúncia, ou de ofício, condutas em desacordo com as normas nele previstas, quando praticadas pelas autoridades a ele submetidas; dirimir dúvidas de interpretação sobre as normas do Código de Ética Profissional do Servidor Público Civil do Poder Executivo Federal de que trata o Decreto no 1.171/1994; coordenar, avaliar e supervisionar o Sistema de Gestão da Ética Pública do Poder Executivo Federal (COMISSÃO DE ÉTICA PÚBLICA, 2015).

\section{A baixa credibilidade do serviço público}

No Decreto no 1.171/94 as regras deontológicas estipuladas aos servidores públicos federais são: a dignidade, o decoro, o zelo, a eficácia e a consciência dos princípios morais. Estes são primados maiores que devem nortear o servidor público, seja no exercício do cargo ou função, ou fora dele, já que refletirá o exercício da vocação do próprio poder estatal. Seus atos, comportamentos e atitudes serão direcionados para a preservação da honra e da tradição dos serviços públicos. O servidor público não poderá jamais desprezar o elemento ético de sua conduta. Assim, não terá que decidir somente entre o legal e o ilegal, o justo e o injusto, o conveniente e o inconveniente, o oportuno e o inoportuno, mas principalmente entre o honesto e o desonesto, consoante as regras contidas no art. 37 , caput, e $\S 4^{\circ}$, da Constituição Federal (BRASIL, 1994).

As instituições públicas são pilares de sustentação dos governos e traduzem para a materialidade os serviços públicos prestados aos cidadãos. Um dos pontos de atuação do código de ética no serviço público federal, em especial para a alta administração, é a transparência do processo decisório. Segundo Carneiro (1998), este elemento é de suma importância para sustentação da confiança dos governados em seus governantes e da população para com o serviço público. Com a rica gama de princípios éticos que cerceiam a atividade dos servidores públicos federais resta claro que as normas estão instituídas e são públicas e notórias quais as condutas consideradas permitidas pelos servidores públicos federais, contudo a confiabilidade do cidadão nos integrantes dos entes do Estado continua a diminuir e perdura na cultura brasileira a imagem de que o servidor público é suscetível a corrupção e ao mau serviço prestado na sua atuação.

A pesquisa do IBOPE Inteligência sobre o Índice de Confiança Social (ICS) ${ }^{2}$ que investiga a confiança da sociedade civil sobre setores públicos e privados, revela redução nos índices de confiança das instituições públicas gradualmente de 2009 a 2015.

${ }^{2}$ Disponível em: <http://www.ibopeinteligencia.com/arquivos/antigos/ics_brasil.pdf> 


\section{ICS - Índice de Confiança Social}

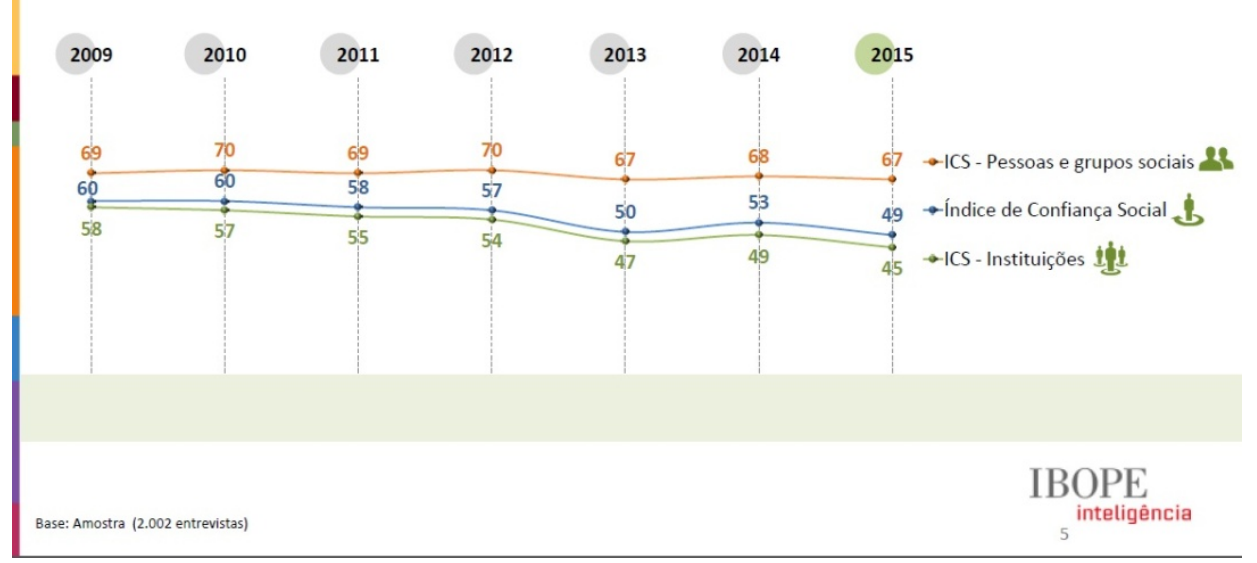

Fonte: Índice de Confiança Social, IBOPE INTELIGÊNCIA

Pode-se atribuir a esta diminuição de confiança os recorrentes casos de corrupção e a baixa qualidade dos serviços públicos. A questão da baixa qualidade dos serviços públicos é diagnosticada a considerável tempo, e apesar dos avanços, continua a pesar negativamente na avaliação do cidadão. Cada vez que um cidadão é mal atendido em uma instituição pública, em que não tem acesso a um serviço público de qualidade ou simplesmente não consegue atendimento, a avaliação do serviço público alimenta a cultura de baixa confiança nos serviços prestados pelo Estado. De acordo com Carneiro (1998), a persistência de uma visão negativa sobre a conduta do setor público é preocupante, pois alimenta o descrédito a respeito do próprio regime democrático de governo e revela um ceticismo intrínseco do povo em relação à ética praticada pelo Estado. Complementa o autor "A associação entre maus serviços e conduta eticamente inadequada é certamente inevitável, até porque, na percepção popular, um mau serviço é "moralmente" condenável".

Um atendimento de qualidade ao cidadão não pode ser exceção, mas sim a regra. Quaisquer que sejam os motivos negativos que influenciam essas situações: más condições de trabalho, salários defasados ou até mesmo atrasados, burocracias do sistema e etc., o servidor público federal em qualquer situação não pode desprezar o elemento ético em sua conduta e não pode deixar de observar as disposições do código de ética: "Tratar mal uma pessoa que paga seus tributos direta ou indiretamente significa causar-lhe dano moral." (BRASIL,1994)

Além do código de ética, os servidores federais estão sujeitos ao Código Penal, ao Código Civil e a Lei de Responsabilidade Fiscal. É fato que o excesso de normas causa fadiga no sistema, como ressaltado por Carneiro (1998) "a percepção é de que não somente se exige do servidor que ele trabalhe com maior eficiência, menores recursos e remuneração insuficiente, mas também que o faça sob o manto da suspeita permanente de transgressões éticas". O excesso de legislações para policiar a atividade do servidor público, e nesse meandro podemos questionar também que na legislação brasileira como um todo existe um excesso de normas e regras, todo o emaranhado jurídico em que se fazem necessários para regular os mais diversos tipos de relações físicas e jurídicas para buscar uma convivência harmoniosa dos indivíduos da sociedade, expõe uma reflexão sobre a conduta ética da sociedade brasileira e sua construção de conceito morais.

Toda a corrupção observada no cenário da política nacional expõe uma triste realidade: "Não existe país no mundo em que o governo seja corrupto e a população honesta e vice-versa" Leandro Karnal (2016). Os brasileiros estão inseridos em uma cultura do "jeitinho" em que para 
tudo existe uma forma de conseguir algo em detrimento dos demais. Aqueles que conseguem marcar uma consulta médica com agilidade porque conhecem alguém que trabalha no posto de saúde, aqueles que andam pelo acostamento das rodovias enquanto os demais aguardam parados no trânsito lento, os que falsificam carteirinha de estudante, os que furam fila, os que aceitam troco à maior, os que sonegam impostos... São tantos os exemplos de pequenas corrupções do dia a dia que a reflexão sobre ética no serviço público federal acaba se tornando uma reflexão sobre a nossa sociedade.

\section{CONCLUSÃO}

O presente ensaio teve como objetivo conceituar o termo ética, contextualizar o código de ética dos servidores públicos federais e instigar a reflexão sobre a ética (ou a falta dela) no serviço público federal e na sociedade em geral.

Os resultados alcançados com a pesquisa bibliográfica de autores que propõem um debate sobre os conceitos de ética e moral demonstram que a conduta ética é regida pela aceitação coletiva dos conceitos morais, onde os códigos de ética auxiliam as categorias profissionais na conduta profissional e o Decreto no 1.171/94 institui os parâmetros de ética que devem ser observados pelos servidores públicos federais.

Pode-se inferir que a ética é parte integrante da convivência em sociedade dos homens e tem como finalidade regular as relações humanas e profissionais. A ética não existe sem os preceitos da moral, que se originam do consciente e caráter dos indivíduos e se estabelecem na aceitação comum pelos demais integrantes de uma comunidade. Para afirmação dos conceitos morais e éticos são elaborados os códigos de ética que compilam as normas e condutas que orientam os profissionais de determinada área para uma atuação dentro dos preceitos da categoria profissional. O Decreto no 1.171/94 orienta e institui os parâmetros de ética que devem ser observados pelos servidores públicos federais. Salienta-se que o código de ética do servidor público federal em uma análise mais profunda, instiga a confiança da sociedade nas instituições públicas e no sistema de governo, uma vez que um servidor público materializa em si a representação da instituição em que trabalha e sua conduta é observada como a conduta da instituição, sendo indissociável o julgamento da conduta ética.

A moralidade da Administração Pública não se limita à distinção entre o bem e o mal, devendo ser acrescida da ideia de que o fim é sempre o bem comum. $O$ equilíbrio entre a legalidade e a finalidade, na conduta do servidor público, é que poderá consolidar a moralidade do ato administrativo. A remuneração do servidor público é custeada pelos tributos pagos direta ou indiretamente por todos, até por ele próprio, e por isso se exige, como contrapartida, que a moralidade administrativa se integre no Direito, como elemento indissociável de sua aplicação e de sua finalidade, erigindo-se, como consequência, em fator de legalidade. $O$ trabalho desenvolvido pelo servidor público perante a comunidade deve ser entendido como acréscimo ao seu próprio bem-estar, já que, como cidadão, integrante da sociedade, o êxito desse trabalho pode ser considerado como seu maior patrimônio (BRASIL, 1994).

O Código de ética elaborado para os servidores públicos federais demonstra-se uma ferramenta clara e completa sobre os princípios deontológicos a serem observados e sobre as condutas de comportamento que regem a atividades profissionais. Inclusive o Código prevê a criação de comissões de ética que serão compostas por servidores e empregados da instituição, e designados pelo dirigente máximo da respectiva entidade ou órgão, para desempenhar atividades consultivas, dirimir dúvidas, supervisionar a observância do Código de Conduta da Alta Administração 
Federal, dentre outras funções são, portanto, unidades dentro das instituições que devem zelar ela observância do Código de Ética.

Contudo, observa-se que os desvios de comportamentos que culminam em comportamento aético são observados em vários níveis da sociedade brasileira. A questão latente é como solucionar a questão do comprometimento ético perante a enraizada cultura brasileira do "jeitinho" e das pequenas corrupções do dia a dia que por vezes não são sequer percebidas como erradas pelos indivíduos e por vezes a ideologia é de que quem não o faz é que é bobo e não está tendo um comportamento inteligente. Combater esse tipo de inversão de valores é uma necessidade urgente se queremos presenciar um país melhor no futuro. A discussão do tema e a exposição dos "contraventores do comportamento ético" às causas e consequências de seus atos são caminhos iniciais para reverter o quadro.

Toda essa discussão tem que passar também pela educação. No âmbito do serviço público o trabalho pedagógico de disseminação dos preceitos dos códigos de ética do serviço público federal, com vistas a ampliar sua compreensão, instituí-lo na cultura organizacional e culminar com o julgamento ético na ação que o servidor realiza, são ações a serem trilhadas incessantemente na administração pública, pois de acordo com Carneiro (1998), os procedimentos administrativos e os padrões de conduta exigidos não são do pleno conhecimento dos servidores públicos.

Portanto, o debate sobre comportamento ético deve ser ampliado no âmbito das instituições públicas e estendido às cadeiras acadêmicas, às escolas de base, à formação do cidadão. Pensar num Brasil do futuro com diminuição nos níveis de corrupção passa primeiro pela discussão de observância de comportamento ético pelos indivíduos da sociedade, pois já observava Karl Marx (1818 - 1883) "o homem é produto do meio" e temos que ter consciência de formar cidadãos éticos que representarão o nosso futuro na nação e por consequência, em todas suas instituições.

\section{REFERÊNCIAS}

Amorim, S. N. D. (2014). Ética na esfera pública: a busca de novas relações Estado/Sociedade. Revista do Serviço Público, 51(2), 94-104.

Barroco, M. L. S. (2001). Ética e Serviço Social: fundamentos ontológicos. Cortez.

Carneiro, J. G. P. (2014). O aprimoramento da conduta ética no serviço público federal. Revista do Serviço Público, 49(3), 120-133.

Chauí, M. (1999). Convite à filosofia. São Paulo: Ática.

Código de Conduta da Alta Administração Federal, de 21 de agosto de 2000. Disponível em: http://www.planalto.gov.br/ccivil_03/codigos/codi_conduta/cod_conduta.htm

Comissão de Ética Pública. (n.d.). Recuperado em 16 de agosto de 2015, de http://etica.planalto.gov.br/sobre-a-cep/institucional-1

Cortella, M. S. (2009). Qual é a tua obra?: inquietações propositivas sobre gestão, liderança e ética. Vozes.

Decreto no 1.171, de 22 de junho de 1994. Aprova o Código de Ética Profissional do Servidor Público Civil do Poder Executivo Federal. Disponível em: http://www.planalto.gov.br/ccivil_03/decreto/d1171.htm

dos Santos Alves, F. J., Lisboa, N. P., Weffort, E. F. J., \& Antunes, M. T. P. (2007). Um estudo empírico sobre a importância do código de ética profissional para o contabilista. Revista Contabilidade \& Finanças, 18(spe), 58-68. 
Escola de Administração Pública. (2012). Ética e Serviço Público: A Conduta no Serviço Público. Disponível em: https://enapvirtual.enap.gov.br/moodledataenap/repository/etica_servico_publico_st/biblio teca/Etica_-_Modulo_3.pdf.

Hegel, G. W. F. (1991). Lecciones sobre la filosofía de la historia universal. Introducción general (Vol. 5). Universitat de València.

Ibope. (2015). Índice de Confiança Social 2015. Disponível em http://www.ibopeinteligencia.com/arquivos/antigos/ics_brasil.pdf.

Karnal, L. Conversando sobre ética nas organizações. Francisco Beltrão, 12 de maio de 2016. Conselho Regional de Administração.

Moreira, J. M. (2002). A ética empresarial no Brasil. São Paulo: Editora Pioneira Thomson Leatning.

Motta, N. D. S. (1984). Ética e vida profissional. Rio de Janeiro: Âmbito Cultural, 984, 09.

Neves, N. M. B. C. (2009). Códigos de conduta: abordagem histórica da sistematização do pensar ético. Revista Bioética, 16(1).

Silva, V. G., Gomes, J. S. (2009). O uso do Código de Conduta Ética como instrumento de controle gerencial: estudo de casos em empresas internacionalizadas. Revista Contemporânea de Contabilidade, v. 5, n. 10, p. 111-128. Disponível em: https://periodicos.ufsc.br/index.php/contabilidade/article/view/21758069.2008v5n10p111/11125.

Singer, P., \& Xavier, A. (2002). Vida ética: os melhores ensaios do mais polêmico filósofo da atualidade. Ediouro.

Tomanik, E. A. (2008). A ética e os comitês de ética em pesquisa com seres humanos. Psicologia em estudo, v. 13, n. 2, p. 395-404.

Vásquez, A. S. (1995). Ética. 15o edição. Rio de Janeiro: Civilização Brasileira. 